\title{
BMJ Open Impact of a combined community and primary care prevention strategy on all-cause and cardiovascular mortality: a cohort analysis based on 1 million person-years of follow-up in Västerbotten County, Sweden, during 1990-2006
}

\author{
Yulia Blomstedt, ${ }^{1,2}$ Margareta Norberg, ${ }^{1,2}$ Hans Stenlund, ${ }^{1}$ Lennarth Nyström, ${ }^{1}$ \\ Göran Lönnberg, ${ }^{1}$ Kurt Boman, ${ }^{3,4}$ Stig Wall, ${ }^{1}$ Lars Weinehall ${ }^{1,2}$
}

To cite: Blomstedt $Y$, Norberg M, Stenlund $\mathrm{H}$, et al. Impact of a combined community and primary care prevention strategy on all-cause and cardiovascular mortality:

a cohort analysis based on 1 million person-years of follow-up in Västerbotten County, Sweden, during 1990-2006. BMJ Open 2015;5:e009651. doi:10.1136/bmjopen-2015009651

- Prepublication history for this paper is available online. To view these files please visit the journal online (http://dx.doi.org/10.1136/ bmjopen-2015-009651).

Received 6 August 2015 Revised 11 November 2015 Accepted 12 November 2015

CrossMark

For numbered affiliations see end of article.

Correspondence to Dr Lars Weinehall; lars.weinehall@umu.se

\section{ABSTRACT}

Objective: To evaluate the impact of the Västerbotten Intervention Programme (VIP) by comparing all eligible individuals (target group impact) according to the intention-to-treat principle and VIP participants with the general Swedish population.

Design: Dynamic cohort study.

Setting/participants: All individuals aged 40,50 or 60 years, residing in Västerbotten County, Sweden, between 1990 and 2006 ( $N=101$ 918) were followed from their first opportunity to participate in the VIP until age 75, study end point or prior death.

Intervention: The VIP is a systematic, long-term, county-wide cardiovascular disease (CVD) intervention that is performed within the primary healthcare setting and combines individual and population approaches. The core component is a health dialogue based on a physical examination and a comprehensive questionnaire at the ages of 40,50 and 60 years.

Primary outcomes: All-cause and CVD mortality. Results: For the target group, there were 5646 deaths observed over 1054607 person-years. Compared to Sweden at large, the standardised all-cause mortality ratio was $90.6 \%$ (95\% Cl $88.2 \%$ to $93.0 \%)$ : for women $87.9 \%$ (95\% Cl $84.1 \%$ to $91.7 \%)$ and for men $92.2 \%$ (95\% Cl $89.2 \%$ to $95.3 \%$ ). For CVD, the ratio was $95.0 \%$ (95\% Cl $90.7 \%$ to $99.4 \%)$ : for women $90.4 \%$ (95\% Cl 82.6\% to $98.7 \%$ ) and for men $96.8 \%$ (95\% Cl 91.7 to 102.0). For participants, subject to further impact as well as selection, when compared to Sweden at large, the standardised all-cause mortality ratio was $66.3 \%$ ( $95 \% \mathrm{Cl} 63.7 \%$ to $69.0 \%$ ), whereas the CVD ratio was $68.9 \%(95 \% \mathrm{Cl} 64.2 \%$ to $73.9 \%)$. For the target group as well as for the participants, standardised mortality ratios for all-cause mortality were reduced within all educational strata.

Conclusions: The study suggests that the VIP model of CVD prevention is able to impact on all-cause and

\section{Strengths and limitations of this study}

- The Västerbotten Intervention Programme is a systematic, long-term, county-wide cardiovascular disease intervention performed within the primary healthcare setting and combining individual and population approaches.

- The study evaluates the long-term mortality outcome in a dynamic cohort design based on 1 million person-years, and for target and participant groups.

- The intention-to-treat approach is employed to avoid selection bias commonly present when addressing participants only.

- Interventions that are successfully integrated into primary healthcare, and employ a mixed individual and population-wide approach, are also able to reach and benefit disadvantaged groups.

cardiovascular mortality when evaluated according to the intention-to-treat principle.

\section{INTRODUCTION}

In spite of decades of rigorous research, cardiovascular disease (CVD) remains the main cause of death globally, ${ }^{1}$ which calls for mobilisation of knowledge on proven effective, efficient and sustainable interventions. ${ }^{2}$

It has been repeatedly shown that changes in behavioural risk factors such as physical inactivity, tobacco smoking, harmful use of alcohol and unhealthy diet can significantly modify CVD risk. ${ }^{3}$ Moreover, these risk factors can be efficiently addressed in low- 
income and high-income countries using cost-effective interventions combining population and individual approaches in primary healthcare (PHC) ${ }^{4}$ The recommended strategies include promotion of a healthy lifestyle on community and individual levels, screening, counselling and motivational interventions ${ }^{5}$ as well as, or in addition to, evidence-based pharmacological treatments targeting conventional risk-factors (hypertension, diabetes, dyslipidaemia). However, the evidence on the effectiveness of community-based approaches has been scarce and at times contradictory, giving rise to doubt and criticism. ${ }^{6} 7$

In this paper, we explore the importance of cardiovascular health promotion and disease prevention using a combined population and individual approach, analysing the experience of the Västerbotten Intervention Programme (VIP). VIP is an ongoing low-intensity community intervention in northern Sweden, where primary care plays a key role in providing continuity and structure for prevention efforts. This paper reports the longterm impact of the VIP on all-cause and CVD mortality during 1990-2006.

\section{METHODS}

\section{Setting: the VIP}

CVD mortality gradually increased in Sweden, starting at the beginning of the 20th century. This transition was particularly marked in the northernmost counties of Sweden, with CVD progressing from an essentially neglected component of total mortality to the leading cause of death in the 1970s. In the early $1980,{ }^{8}$ the age-adjusted CVD mortality rate in Västerbotten County among 15-74-year-olds was the highest in Sweden, being $40 \%$ higher than in the county with the lowest mortality. ${ }^{9}$

In 1984, responding to these alarming findings, the Västerbotten County Council decided to develop a model for a population-oriented programme to address CVD and diabetes prevention. A systematic, joint undertaking was designed with PHC as the coordinating hub. $^{10}$

A feasibility study was carried out in one of the communities of the Västerbotten county and combined a strategy to reach all middle-aged persons individually with a population-wide strategy designed to reach the community as a whole with a variety of activities. ${ }^{11}$ The individual strategy included invitation of all citizens at ages 30, 40, 50 and 60 years to a health examination at their local PHC centre. Examples of community-based activities included meetings for the general public with discussions about public health issues, information in local media, in schools and at workplaces about health promotion and healthy lifestyles, NGO activities, labelling of healthy foods in local stores. At the 10-year evaluation of the feasibility study, the age and education-adjusted CVD mortality rate was estimated to be reduced by $36 \%$ in the intervention area, according to the North Karelia CHD risk equation, compared to $1 \%$ in the reference area (MONICA Northern Sweden). ${ }^{12}$ The greatest benefit of the intervention was seen in the group with the lowest education.

In 1990, the core intervention components-physical examination, questionnaire and health dialogue (box 1) -were identified and implemented in all 40 PHC centres in the county. ${ }^{11}$ This all-county initiative received the name of the VIP which is still ongoing. On the basis of current strategic decisions, the VIP will continue at least until the year 2020.

In the current study, the period 1990-2006 during which the participation rate increased from $55 \%$ to $65 \%$ is evaluated. In 1995, the 30-year-olds were excluded for economic reasons. As reported elsewhere, participants and non-participants did not differ substantially in terms of socioeconomic status. ${ }^{13} 14$

The VIP is overseen by a scientific advisory board from Umeå University representing cardiology, nutritional research, family medicine, pedagogy and epidemiology. The procedures and the manual are regularly updated according to medical evidence and current national and international guidelines. ${ }^{15} \mathrm{~A}$ county-wide support structure organised at the County council includes regular feedback about the VIP results as well as education and training of the staff that provide the VIP in daily practice.

Box 1 Core components of the Västerbotten Intervention Programme (VIP)

\section{The VIP examination}

After an overnight fast, the participants visit their primary healthcare centre for an oral glucose tolerance test, performed according to the WHO criteria, and measurements of lipids, body mass index and blood pressure. ${ }^{11}$ Participants are also asked to donate blood for research purposes. These samples are stored at the Umeå University Medical Biobank. ${ }^{16}$

\section{Questionnaire}

The participants complete a comprehensive questionnaire that covers socioeconomic and psychosocial conditions, self-reported health, family history of cardiovascular disease and diabetes, quality of life, and lifestyle habits (physical activity, alcohol and tobacco consumption, and eating habits).

A health dialogue with each participant

The results of the examination and the questionnaire responses are discussed individually with a trained nurse. This dialogue is based on the method of motivational interviewing accompanied by a pedagogical tool-a risk profile drawn for each participant in the form of a star-which provides a visual representation of the link between the participant's risk factors and lifestyle habits and facilitates accurate risk perception and motivation for lifestyle modification. When appropriate, follow-up visits are recommended, and, referrals to the participant's family doctor for further assessment and pharmacological treatment according to clinical guidelines are done. A more detailed description of the VIP design and procedures has been published previously. ${ }^{11}$ 


\section{Hypothesis and objective}

Our hypothesis is that, if the VIP model is able to reduce the number of premature all-cause and CVD deaths, this would be observable

A. Among all individuals who were eligible for VIP regardless of their participation status $(n=101918)$ (target group impact);

B. Among the VIP participants $(\mathrm{n}=59629)$-individuals who participated in all components of VIP as described in Textbox 1 at all (two) or any opportunities during the 16 years of the follow-up period (effect to a larger extent as a combined consequence of selection bias and intervention impact);

C. Among all educational groups.

\section{Study population}

The study population included all individuals residing in Västerbotten who turned 40,50 or 60 years between 1990 and 2006. The reference population was the whole Swedish population aged 40,50 or 60 years residing in Sweden, including Västerbotten, between 1990 and 2006 $(n=3472$ 164). Västerbotten County comprises $3 \%$ of the national population and is sparsely populated with about five inhabitants/square kilometre as compared with 24 for all Sweden. The level of education in Västerbotten is slightly higher than that of Sweden. In 2014, 27\% of the population aged 25-64 in Västerbotten and $26 \%$ in Sweden had high education (3 years of postsecondary or postgraduate education), whereas $9 \%$ and $13 \%$, respectively, had low education (primary and lower secondary education).

\section{Study design}

A dynamic cohort approach was adopted to evaluate the VIP effect in this observational retrospective study. Person-time at risk (the follow-up time) began to accumulate from the time the individual entered the cohort/study population on turning 40,50 or 60 years between 1990 and 2006 until age $74,{ }^{i}$ study end point on 31 December 2006 or prior death. No individuals were lost to follow-up.

\section{Data}

Data were obtained from The Linnaeus Database at the Centre for Population Studies, Umeå University, Sweden. ${ }^{17}$ In this database, individual VIP records are linked with national data on morbidity, mortality from the National Board of Health and Welfare ${ }^{18}$; and socioeconomic status from Statistics Sweden. ${ }^{19}$ These national data are of very high quality with no missing values.

\section{Primary outcomes}

Outcome variables included all-cause mortality and CVD mortality (diseases of the circulatory system in ICD 9:

\footnotetext{
${ }^{\mathrm{i}}$ The upper limit of 74 year old was chosen to be congruent with age strata in national statistics.
}

390-459 and in ICD 10: I10-99 as the underlying cause of death).

\section{Explanatory variables}

Baseline explanatory variables included:

-VIP participation status (non-participant/participant);

- Sex

- Age at entry (40, 50 or 60 years);

- Education-high (college or higher, $\geq 13$ years of schooling), middle (residential college for adult education or high school, 10-12 years), or low (elementary and comprehensive compulsory school, $5-9$ years).

\section{Statistical analyses}

Since a comparison between participants and nonparticipants is difficult to interpret in view of the potential overestimation of the effect caused by the selection bias, both the target group and participants were compared to the same reference, here the Swedish population. The impact of VIP was evaluated by comparing all-cause and CVD mortality with the general Swedish population for women and men in terms of age and calendar time standardised mortality ratios (SMRs) with 95\% CIs. SMRs were calculated separately for women and men and for educational groups. On the basis of rates from the reference population in the same age, sex, period and educational groups applied to the person-year distribution of the study groups, the expected number of deaths was calculated. The difference between observed and expected deaths was taken as the estimate of prevented premature deaths.

A key measure of the impact of an intervention is the extent to which it reaches lower socioeconomic groups and therefore counteracts prevailing socioeconomic gaps in health. It is this aspect of an intervention that may ultimately lead to a narrowing of the SES mortality gap. We addressed this issue by examining education as a potential modifier of the intervention's impact on mortality.

Cohort Software and STATA software package 10.1 were used for statistical analyses.

\section{RESULTS}

Baseline characteristics of both the target and participant groups, compared to the all-Sweden reference group, are presented below, table 1. Participants differed marginally on background variables from the target group and the non-participant group, as also shown elsewhere. ${ }^{13} 14$

\section{Target group}

Among women, there were 2071 all-cause deaths during 522531 person-years resulting in an SMR of 87.9 (95\% CI 84.1 to 91.7), while among men there were 3575 allcause deaths during 531346 person-years resulting in an SMR of 92.2 (95\% CI 89.2 to 95.3). Thus, the overall 
Table 1 Baseline characteristics

\begin{tabular}{|c|c|c|c|c|c|c|}
\hline \multirow[b]{2}{*}{ Baseline characteristics } & \multicolumn{2}{|c|}{ Sweden ( $n=3472$ 164) } & \multicolumn{2}{|c|}{$\begin{array}{l}\text { Target group } \\
(\mathrm{n}=101918)\end{array}$} & \multicolumn{2}{|c|}{$\begin{array}{l}\text { Participants } \\
(n=59629)\end{array}$} \\
\hline & $\mathbf{n}$ & Per cent & $\mathbf{N}$ & Per cent & $n$ & Per cent \\
\hline \multicolumn{7}{|l|}{ Sex } \\
\hline Men & 1753256 & 50.5 & 51889 & 50.9 & 28361 & 47.6 \\
\hline Women & 1718908 & 49.5 & 50029 & 49.1 & 31268 & 52.4 \\
\hline \multicolumn{7}{|l|}{ Age at entry } \\
\hline 40 & 1358966 & 39.1 & 40054 & 39.3 & 22660 & 38.0 \\
\hline 50 & 1252210 & 36.1 & 35535 & 34.9 & 20978 & 35.2 \\
\hline 60 & 860988 & 24.8 & 26329 & 25.8 & 15991 & 26.8 \\
\hline \multicolumn{7}{|l|}{ Education } \\
\hline High & 819046 & 23.6 & 24414 & 24.0 & 14029 & 24.6 \\
\hline Middle & 1573423 & 45.3 & 51086 & 50.1 & 30786 & 48.0 \\
\hline Low & 1079695 & 31.1 & 26418 & 25.9 & 14814 & 27.4 \\
\hline
\end{tabular}

reduction in all-cause mortality was $12.1 \%$ for women and $7.8 \%$ for men, which resulted in an estimate of 587 prevented premature deaths. This death rate reduction was also significant within all but one educational strata, with no significant differences in reduction between educational groups for either women or men (table 2). Deaths due to CVD comprised $32.7 \%$ of all-cause mortality. The overall reduction in CVD mortality was $9.6 \%$ for women and 3.2\% for men, resulting in 96 prevented premature CVD deaths (table 2).

\section{Participants}

Among participating women, there were 966 deaths during 329490 person-years, while among men there were 1477 deaths during 292809 person-years. The reduction in all-cause mortality was $35.6 \%$ for women and $32.4 \%$ for men, a deficit of 1241 deaths (table 3). The reduction in CVD mortality was $36.6 \%$ for women and $28.7 \%$ for men, corresponding to 353 deaths (table 3 ).

Since the net effect was 587 prevented all-cause deaths among the entire eligible cohort (target group) versus 1241 fewer than expected deaths among the participants when using the common reference population, the excess all-cause mortality among non-participants was 654 deaths. The corresponding number of excess CVD deaths among non-participants was 257. This may serve as a quantitative measure of the negative selection among non-participants.

Figures 1 and 2 summarise the potential impacts in terms of 'prevented' deaths as measured by the differences between the number of deaths that were actually observed and the number of deaths that would have occurred in the target group had this been subjected to the age-specific, sex-specific and time-specific death rates of the all-Sweden reference group.

Despite the fact that the relative gains were as high among the better educated compared to the less educated, it generally translates to a rather few averted cases originating from the high educated. The pattern in figure 1 illustrates that the most all-cause deaths were averted for women in the middle-education group, while for men the most prevented deaths were found among the lowest educated. While being partly an effect of the varying death rates across educational groups and sexes, this also quantifies the potential intervention gains in absolute numbers.

As can be seen in figure 2, the gains in terms of averted CVD deaths were smaller and less consistent across educational groups, a paradox that is further discussed below.

\section{DISCUSSION}

We have previously documented that during the study period (1990-2006), smoking prevalence among VIP participants has decreased for men and women, ${ }^{20}$ the overall trend of increasing obesity has slowed, ${ }^{21}$ the prevalence of hypercholesterolaemia ${ }^{22}$ and hypertension $^{23}$ has significantly decreased, physical activity has increased, ${ }^{24}$ and over half of the participants with poor self-reported health at baseline reported better selfreported health at a 10-year follow-up. ${ }^{25}$ In contrast, the level of mean fasting glucose concentration has increased $0.5 \mathrm{mmol} / \mathrm{L}$, resulting in increased diabetes prevalence, particularly among men. ${ }^{26}$ Socioeconomic differences in the prevalence of these risk-factors still exist among the VIP participants. ${ }^{202124}$ This study is the first to assess the mortality consequences for the entire eligible target group of the VIP irrespective of participation status.

\section{Impact on all-cause and CVD mortality}

The principal finding in this study is that there is a significant impact of the VIP model on all-cause and CVD mortality. Atherosclerotic CVD, myocardial infarction and stroke are the leading causes of premature death and are all related to modifiable behavioural risk factors. ${ }^{3}$ All cancers, when considered together, do cause a larger number of premature deaths than those attributable to CVD. However, some of the most 
Table 2 All-cause and CVD mortality stratified by educational level in the Västerbotten Intervention Programme cohort (target group) followed from 1990 to 2006 , as compared with all of Sweden

\begin{tabular}{|c|c|c|c|c|c|c|c|c|c|}
\hline \multirow[b]{2}{*}{ Gender } & \multirow[b]{2}{*}{ Educa-tional Level } & \multicolumn{4}{|c|}{ All-cause mortality } & \multicolumn{4}{|c|}{ CVD mortality } \\
\hline & & Ob-served & Ex-pected & SMR (\%) & $95 \% \mathrm{CI}$ & Ob-served & Ex-pected & SMR (\%) & $95 \% \mathrm{Cl}$ \\
\hline \multirow[t]{4}{*}{ Women } & Low & 886 & 979 & 90.5 & 84.7 to 96.6 & 254 & 266 & 95.4 & 84.2 to 107.7 \\
\hline & Middle & 884 & 1031 & 85.8 & 80.2 to 91.6 & 192 & 219 & 87.5 & 75.7 to 100.6 \\
\hline & High & 301 & 347 & 86.7 & 77.3 to 96.9 & 39 & 51 & 76.7 & 55.3 to 103.9 \\
\hline & Total & 2071 & 2357 & 87.9 & 84.1 to 91.7 & 485 & 536 & 90.4 & 82.6 to 98.7 \\
\hline \multirow[t]{4}{*}{ Men } & Low & 1700 & 1844 & 92.2 & 87.8 to 96.6 & 683 & 724 & 94.4 & 87.4 to 101.6 \\
\hline & Middle & 1473 & 1596 & 92.3 & 87.6 to 97.1 & 557 & 544 & 102.3 & 94.0 to 110.8 \\
\hline & High & 402 & 436 & 92.2 & 83.4 to 101.5 & 123 & 140 & 87.6 & 68.7 to 97.9 \\
\hline & Total & 3575 & 3876 & 92.2 & 89.2 to 95.3 & 1363 & 1408 & 96.8 & 91.7 to 102.0 \\
\hline Grand total & & 5646 & 6233 & 90.6 & 88.2 to 93.0 & 1848 & 1944 & 95.0 & 90.7 to 99.4 \\
\hline
\end{tabular}

Table 3 All-cause and CVD mortality stratified by educational level in the Västerbotten Intervention Programme participants followed from 1990 to 2006 , as compared with all of Sweden

\begin{tabular}{|c|c|c|c|c|c|c|c|c|c|}
\hline \multirow[b]{2}{*}{ Gender } & \multirow{2}{*}{$\begin{array}{l}\text { Educa-tional } \\
\text { Level }\end{array}$} & \multicolumn{4}{|c|}{ All-cause mortality } & \multicolumn{4}{|c|}{ CVD mortality } \\
\hline & & Ob-served & Ex-pected & SMR (\%) & $95 \% \mathrm{Cl}$ & Ob-served & Ex-pected & SMR (\%) & $95 \% \mathrm{Cl}$ \\
\hline \multirow[t]{4}{*}{ Women } & Low & 406 & 604 & 67.3 & 60.9 to 74.0 & 107 & 164 & 65.3 & 53.7 to 78.6 \\
\hline & Middle & 433 & 682 & 63.5 & 57.6 to 69.4 & 91 & 146 & 62.4 & 50.5 to 76.2 \\
\hline & High & 127 & 214 & 59.4 & 49.7 to 70.4 & 18 & 31 & 57.6 & 35.1 to 89.1 \\
\hline & Total & 966 & 1500 & 64.4 & 60.4 to 68.6 & 216 & 341 & 63.4 & 55.3 to 72.7 \\
\hline \multirow[t]{4}{*}{ Men } & Low & 699 & 1015 & 68.9 & 63.9 to 74.2 & 281 & 399 & 70.5 & 62.6 to 79.1 \\
\hline & Middle & 600 & 924 & 65.0 & 59.9 to 70.3 & 237 & 316 & 75.0 & 65.8 to 85.0 \\
\hline & High & 178 & 245 & 72.5 & 62.4 to 83.8 & 48 & 79 & 60.4 & 45.0 to 79.5 \\
\hline & Total & 1477 & 2184 & 67.6 & 64.2 to 71.2 & 566 & 794 & 71.3 & 65.5 to 77.3 \\
\hline Grand total & & 2443 & 3684 & 66.3 & 63.7 to 69.0 & 782 & 1135 & 68.9 & 64.2 to 73.9 \\
\hline
\end{tabular}




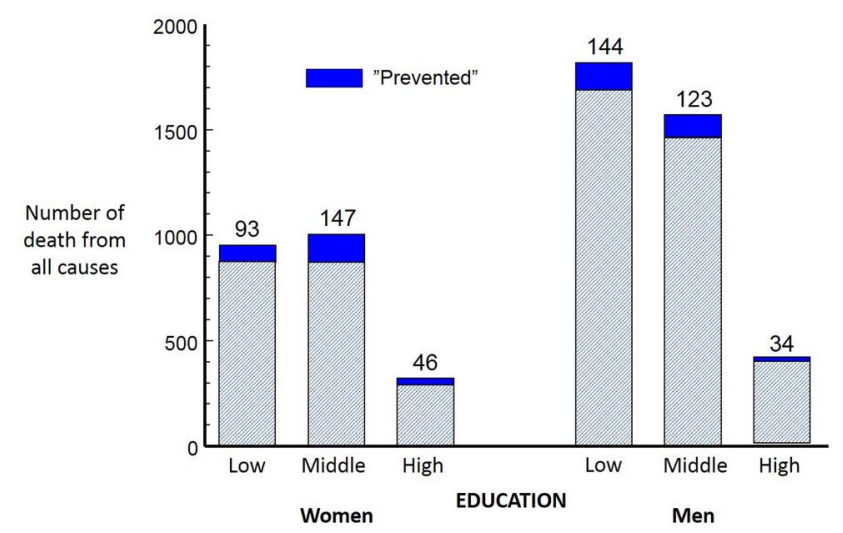

Figure 1 Sex and educational level specific all-cause mortality among the Västerbotten Intervention Programme target group (regardless of participation status). The expected number (observed + prevented) of deaths was estimated from the national age-specific, calendar-specific and sex-specific mortality rates.

common cancers, such as those of the colon, lung and breast, share many risk factors in common with CVD. ${ }^{27-29}$ Therefore, it is not surprising that the VIP intervention, which targets these shared risk factors, may also have an impact on total mortality.

It is reasonable to question whether or not these favourable outcomes can be attributed to the VIP, since the study was not a randomised clinical trial (RCT). However, as argued by Labarthe and Stamler, ${ }^{30}$ rigorous documentation and well-designed comparative evaluation can serve as an admissible source of evidence of programme effectiveness, especially when an RCT approach is inappropriate or not feasible. While the national statistics do show a countrywide reduction in CVD mortality for Sweden as a whole, the reduction in Västerbotten County was greater during 1990-2006.

Surprisingly, women showed the largest age-related decline in CVD and all-cause mortality among the target

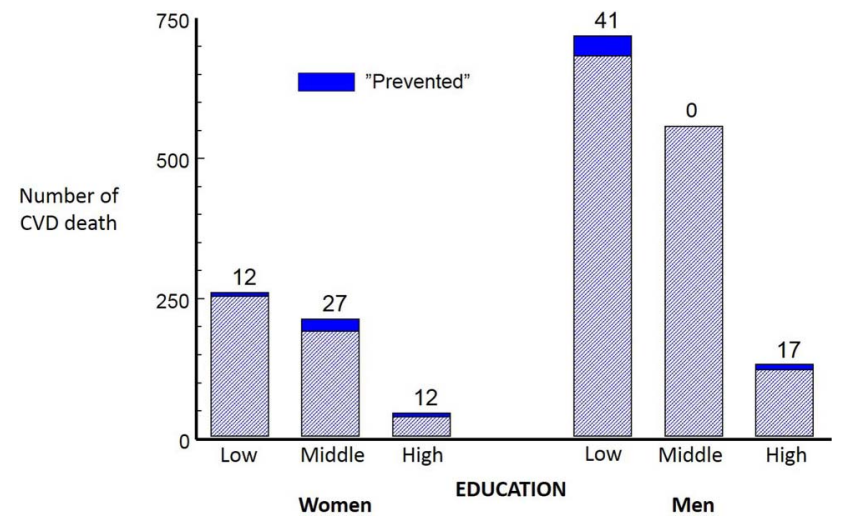

Figure 2 Sex and educational level specific cardiovascular disease (CVD) mortality among the Västerbotten Intervention Programme target group (regardless of participation status) in 1990-2006: Observed and prevented deaths. The expected number (observed + prevented) of deaths was estimated from the national age-specific, calendar-specific and sex-specific mortality rates. group and participants. There may be several reasons behind this finding. One possibility is that the VIP nurses (mostly women) found it more natural to communicate about health issues with women than men. Another possibility might be that middle-aged female participants were more likely to be early adopters and thus more prone to change. An important challenge for the future is to design intervention components that give middle-aged men better support for lifestyle changes.

When discussing the overall cost-utility of a community-oriented endeavour such as the VIP, the following exercise may serve as a relief for interpretation: Hypothetically, should we be able to close the education gap in the cohort-a massive societal undertaking-by theoretically turning all low-educated and middle-educated to high-educated, we could measure a potential outcome by how many fewer deaths would occur in the cohort. Applying population attributable risk calculations then implies that $41 \%$ of the deaths among women and $38 \%$ among men in the combined low and middle educational groups would be averted, resulting in preventing 2184 of the total of 4943 premature deaths observed in these strata. This may be contrasted with the 587 deaths prevented by lowering the overall mortality risks by the VIP.

\section{Impact on socioeconomic inequalities}

It has been suggested elsewhere that community-based interventions might contribute to increased socioeconomic gaps in health status between the different population groups. ${ }^{31}$ In contrast, our analyses suggest that the VIP model was particularly effective in supporting disadvantaged groups, as shown by higher absolute numbers of prevented deaths among the groups with low or middle education. This is an important finding, as socially and economically privileged groups tend to have advantageous risk factor patterns. Thus, population-based preventive programmes are challenged to reduce the risk factor burden without widening the social gap. Few community interventions have been able to report that they did not increase this socioeconomic gap. ${ }^{32}$ The preliminary results of the German Cardiovascular Prevention Study have also indicated larger net reductions in mortality risk in less-educated people after 3.5 years of behaviour-directed intervention. ${ }^{33}$ The Stanford Three-Community Study ${ }^{34}$ and Five-City Project ${ }^{35}$ have shown equal effects of community-wide education programmes on CVD risk factors on low and high socioeconomic groups, whereas the North Karelia Project reported greater changes in the higher socioeconomic groups. ${ }^{31}$

\section{Mechanisms behind the VIP}

Although physical activity has increased in this population, the proportion with sedentary behaviour has been stable and body mass index and blood sugar levels have continued to increase. Comparative data from the 
Northern MONICA study, which covers both the Västerbotten county and the neighbouring county of Norrbotten, show that the decline in blood pressure and cholesterol has been more pronounced in the area where the VIP was implemented. ${ }^{36}$ Several factors may contribute to the VIP effect, including the collaborative partnership between decision-makers, researchers, clinicians (both at PHC centres and specialised heart clinics), health planners and the general public. The ability to customise the programme components to the local context and its expectations may also contribute by bringing trust and legitimacy. However, the most important factor might be the stability, in terms of structure and continuity, that primary care has been able to offer as a hub for preventive service during these 17 years. The staff at the primary care centres base their efforts on knowledge of the population and its social conditions. The relatively high VIP participation rate indicates that the population has taken the programme seriously, as was also recognised by the Commission on Social Determinants of Health in its interim statement of $2007 .{ }^{37}$ The VIP intervention was part of regular primary care, which is why the marginal cost for the programme as a whole was low. ${ }^{38}$ The infrastructure of the VIP with collaboration with local key actors and policies also facilitates the combination of population based and individually based strategies.

The authors of a recently published report on a community-wide CVD programme in Franklin, USA, ${ }^{39}$ attributed the success of their programme to the same factors that we suggest made the VIP successful. As with the VIP, and another well-known successful intervention in North Karelia, Finland, the Franklin intervention was also community-based, integrated with primary care, and had sufficient intensity and duration to demonstrate significant reductions in CVD mortality. The authors contrasted their results with other large community intervention trials in the USA-the Stanford Five City Project, the Pawtucket Heart Health Programme, and the Minnesota Heart Health Programme. None of these other studies observed corresponding mortality reductions, possibly as a consequence of lack of integration with primary care. ${ }^{31}$

Mittelmark et at ${ }^{40}$ have also noted the low degree of healthcare provider involvement in the above-named American prevention programmes and offered some explanation. One key finding was that the healthcare professionals were unwilling to get involved in prevention due to a self-perceived lack of knowledge and competence. Mittelmark et $a t^{40}$ also pointed to the difficulty of financing long-term prevention efforts. Populationoriented efforts can be relatively costly, because they must be designed to reach a large number of Individuals. These efforts also require considerable logistic and technical resources. Paradoxically, the most difficult groups to reach are typically the ones that are in greatest need of the intervention. Mittelmark's conclusion was that if no social organisation or healthcare structure is willing to get involved extensively and on a long-term basis, it is not realistic to carry on populationbased prevention programmes. ${ }^{40}$

In recent years, two reports on the ability of health checks to reduce mortality have received considerable attention. A Cochrane Systematic Review ${ }^{6}$ and a Danish study, Inter $99,^{7}$ both questioned the impact of health checks on this outcome. Both studies concluded that the effects are modest or non-existent, and in the ensuing debate, a number of commentators have questioned the value of these preventive measures. They pointed out that the Inter99 trial was not able to show any target group impact, a position in stark contrast to our findings reported here for the much larger and sustainable VIP study.

The VIP differs from the health check trials cited in these evaluations in that it is individually and population-oriented. Its individually-oriented intervention with a health dialogue is directed at all participants. By combining a community-based strategy with a strategy to reach all middle-aged persons individually, ${ }^{11}$ the programme seeks to instil an increased awareness of the need for prevention efforts in the entire population. In the VIP, in contrast to RCTs where researchers control exposure to the intervention, dissemination of the preventive message through discussions among the population is encouraged by primary care providers.

The VIP screening also provides an opportunity to identify and treat high-risk individuals. This is illustrated by the fact that $25.5 \%$ of male participants and $19.7 \%$ of female participants with hypertension, diabetes or hypercholesterolaemia have been identified and treated. Without the intervention, these conditions might not have been identified or treated for many years.

Although the considerably reduced mortality among participants observed in this study is only partially an intervention effect, it carries an important message to the individual participant and to the nurses who provide the VIP as well as to physicians regarding the potential of primary CVD prevention. Also, it serves to add further motivation for scaling up interventions and increasing participation rates.

It has been shown that when a high-risk approach is combined with a population approach, the two complement one another and achieve a risk-factor reduction beyond what the population strategy alone can achieve. ${ }^{41}$ A combination of population-wide and individual components, where primary care plays a central role in the individually-oriented interventions, might indeed be an effective approach to reduce the NCD burden. ${ }^{4}$ Our results are also in agreement with those from a parallel community intervention and health dialogue project in Habo municipality in Southern Sweden. Ecological analyses of that study showed that changes in lifestyle habits and CVD risk factor burden were more favourable in Habo compared to reference municipalities. Further, the reduction in CVD mortality was more pronounced when compared to similar municipalities 
where no intervention programme had been implemented, as well to Sweden as a whole. ${ }^{42} 43$

One possible explanation for why the trials included in the Cochrane review, as well as the Inter99-study, were not able to show any mortality effect is that they did not benefit from the network activities and public motivation for lifestyle changes that were employed by the VIP. These are accomplished when health counselling and popular health promotion activities are combined and systematically supported by structures in the local community.

The fact that about two-thirds of the invited middle-aged population were willing to participate in individually-oriented activities of the VIP might be viewed as an expression of a readiness for change, which is a key element for successful population interventions.

\section{Strengths and weaknesses}

Primary care in Västerbotten County is generally characterised by a low turnover rate for district staff nurses. Owing to this, the programme itself had continuity in personnel and annual training efforts.

This study applied a cohort approach in which all individuals were followed from their initial eligibility to participate in the VIP. All 40 and 50-year-olds were invited to participate in the VIP at the 10-year follow-up point regardless of whether or not they had participated initially. Thus, some participants who are referred to as 'non-participants' could have participated in the VIP at the second opportunity. The effect of repeated VIP participation will be explored in further studies.

We do not have complete information on whether or not all eligible persons actually receive an invitation to participate. If for some reasons an individual did not receive an invitation (8\% according to the 2001 Västerbotten County Council assessment ${ }^{44}$ ) and did not participate in the VIP for that reason, he/she would still be categorised as a 'non-participant'. We have performed extensive adjustment for confounders and have been unable to identify any other significant differences between the inhabitants of Västerbotten County versus Sweden as a whole. Also, as mentioned earlier, the overall mortality in Västerbotten differs only marginally from that of Sweden. In view of the history of high CVD mortality in Västerbotten, the impact on CVD from VIP is likely to be an underestimation.

The approach to the evaluation that was chosen is subject to question, as complex interventions such as the VIP are difficult to evaluate. Owing to the populationwide approach, informal discussions between participants and non-participants might have contributed to gradually increasing health literacy in the population. Therefore, as discussed previously, we cannot exclude the possibility that non-participants are also influenced by the programme. Moreover, in the evaluation of complex interventions, it is not sufficient to assess only outcomes such as mortality. For a better understanding of which intervention components work and which do not and how these components interact to produce results, further evaluations are called for, including the impact of repeated VIP participation, the VIP's effect on other causes of death, qualitative studies and costeffectiveness analyses.

\section{Conclusions}

These results suggest that the Västerbotten Intervention Programme for CVD prevention is able to reduce allcause and CVD mortality. We claim that interventions that are successfully integrated into PHC and employ a mixed individual and population-wide approach are also able to reach and benefit disadvantaged groups.

\section{Author affiliations}

${ }^{1}$ Epidemiology and Global Health, Department of Public Health and Clinical Medicine, Umeå University, Umeå, Sweden

${ }^{2}$ Centre for Population Studies, Ageing and Living Conditions Programme, Umeå University, Umeå, Sweden

${ }^{3}$ Research Unit Medicine-Geriatric Clinic, Skellefteå County Hospital, Skellefteå, Sweden

${ }^{4}$ Department of Medicine, Department of Public Health and Clinical Medicine, Umeå University, Umeå, Sweden

Acknowledgements The Västerbotten Intervention Programme is carried out with the support of the Västerbotten County Council. The authors are especially grateful to the district nurses in Västerbotten primary care, as their sustainable work with the Västerbotten Intervention Programme made this study possible.

Contributors All authors participated in the design and conduct of the study, contributed to the writing of the manuscript, and read and approved the final manuscript. YB, MN and GL had access to the individual records at the Linneaus database. All authors had full access to the aggregated data from the Linneaus database and national databases, including statistical reports, tables and figures, and can take responsibility for the integrity of the data and the accuracy of the data analysis. YB and LW wrote the introduction. MN, YB and SW wrote the methods and results section. SW, HS, YB and GL made the statistical analysis. YB, LW, MN, KB and SW wrote the discussion section. All authors read and approved the final manuscript. LW is the guarantor.

Funding The research was funded by the Swedish Research Council (grant number K2005-27X-15307 -01AK), and was conducted at the Umeå Centre for Global Health Research, funded by FAS, the Swedish Council for Working Life and Social Research (grant number 2006-1512). The research was also included in the Ageing and Living Conditions Programme at Umeå University and was financed by the Swedish Research Council, (grant number 2006-21576 -36119-66).

Competing interests None declared.

Ethics approval This research was approved by the Regional Ethical Committee, Umeå, Sweden, DNR 07-1420̈ and DNR 08-131M. The VIP participants were informed about the use of data for research purposes.

Provenance and peer review Not commissioned; externally peer reviewed.

Data sharing statement No additional data are available.

Open Access This is an Open Access article distributed in accordance with the Creative Commons Attribution Non Commercial (CC BY-NC 4.0) license, which permits others to distribute, remix, adapt, build upon this work noncommercially, and license their derivative works on different terms, provided the original work is properly cited and the use is non-commercial. See: http:// creativecommons.org/licenses/by-nc/4.0/ 


\section{REFERENCES}

1. WHO. The top 10 causes of death. Fact sheet \#310, 2014. http:// www.who.int/mediacentre/factsheets/fs310/en/ (accessed 2015).

2. WHO. Global status report on non-communicable diseases 2010. Geneva, 2011.

3. Gaziano TA, Bitton A, Anand S, et al. Growing epidemic of coronary heart disease in low- and middle-income countries. Curr Probl Cardiol 2010;35:72-115.

4. World Health Organization. Package of essential noncommunicable (PEN) disease interventions for primary health care in low-resourse settings. Geneva: WHO, 2010.

5. Vartiainen E, Puska $P$, Jousilahti $P$, et al. Twenty-year trends in coronary risk factors in north Karelia and in other areas of Finland. Int J Epidemiol 1994;23:495-504.

6. Krogsboll LT, Jorgensen KJ, Gronhoj Larsen C, et al. General health checks in adults for reducing morbidity and mortality from disease. Cochrane Database Syst Rev 2012;(10):CD009009.

7. Jorgensen T, Jacobsen RK, Toft U, et al. Effect of screening and lifestyle counselling on incidence of ischaemic heart disease in general population: Inter99 randomised trial. BMJ 2014;348:g3617.

8. Weinehall $L$. The emerging epidemic of cardiovascular disease. Scand J Public Health Suppl 2003;61:5-8.

9. Wall S, Rosen M, Nystrom L. The Swedish mortality pattern: a basis for health planning?. Int J Epidemiol 1985;14:285-92

10. Protocol from the Västerbotten County Council board meeting, § 470, December 17 (in Swedish). Umeå: Västerbottens Läns Landsting, 1984.

11. Norberg M, Boman K, Weinehall L. The Västerbotten Intervention Programme: background, design and implications. Glob Health Action 2010;3.

12. Weinehall L, Hellsten G, Boman K, et al. Can a sustainable community intervention reduce the health gap?-10-year evaluation of a Swedish community intervention program for the prevention of cardiovascular disease. Scand J Public Health Suppl 2001;56:59-68.

13. Weinehall L, Hallgren CG, Westman G, et al. Reduction of selection bias in primary prevention of cardiovascular disease through involvement of primary health care. Scand J Prim Health Care 1998;16:171-6.

14. Norberg M, Blomstedt $Y$, Lönnberg G, et al. Community participation and sustainability-evidence over 25 years in the Vasterbotten Intervention Programme. Glob Health Action 2012;5:1-9.

15. Manual 2015, Västerbotten Intervention Program. (In Swedish). ed. Umeå: Västerbotten County Council, 2015.

16. Lenner P, Hallmans G, Weinehall L, et al. [Population-based biological test bank. New possibilities for epidemiologic cancer research]. Lakartidningen 1991;88:4447-9.

17. Malmberg G, Nilsson LG, Weinehall L. Longitudinal data for interdisciplinary ageing research. Design of the Linnaeus Database. Scand J Public Health 2010;38:761-7.

18. Statistical databases - cause of death statistics. http://www. socialstyrelsen.se/statistik/statistikdatabas. Socialstyrelsen [National Board of Health and Welfare].

19. Statistical databases. http://www.ssd.scb.se/databaser/makro/start. asp. Statistics Sweden.

20. Norberg M, Lundqvist G, Nilsson M, et al. Changing patterns of tobacco use in a middle-aged population-the role of snus, gender, age, and education. Glob Health Action 2011;4.

21. Norberg $M$, Lindvall $\mathrm{K}$, Stenlund $\mathrm{H}$, et al. The obesity epidemic slows among the middle-aged population in Sweden while the socioeconomic gap widens. Glob Health Action 2010;3

22. $\mathrm{Ng} \mathrm{N}$, Johnson $\mathrm{O}$, Lindahl $\mathrm{B}$, et al. A reversal of decreasing trends in population cholesterol levels in Vasterbotten County, Sweden. Glob Health Action 2012;5.

23. $\mathrm{Ng} \mathrm{N}$, Carlberg B, Weinehall L, et al. Trends of blood pressure levels and management in Vasterbotten County, Sweden, during 19902010. Glob Health Action 2012;5.
24. $\mathrm{Ng} \mathrm{N}$, Soderman $\mathrm{K}$, Norberg $\mathrm{M}$, et al. Increasing physical activity, but persisting social gaps among middle-aged people: trends in Northern Sweden from 1990 to 2007. Glob Health Action 2011;4:6347.

25. Blomstedt $Y$, Emmelin M, Weinehall L. What about healthy participants? The improvement and deterioration of self-reported health at a 10-year follow-up of the Vasterbotten Intervention Programme. Glob Health Action 2011;4:5435.

26. Lindahl B, Stenlund $\mathrm{H}$, Norberg M. Increasing glucose concentrations and prevalence of diabetes mellitus in northern Sweden, 1990-2007. Glob Health Action 2010;3.

27. Aleksandrova $\mathrm{K}$, Pischon $\mathrm{T}$, Jenab $\mathrm{M}$, et al. Combined impact of healthy lifestyle factors on colorectal cancer: a large European cohort study. BMC Med 2014;12:168.

28. Hoggart $C$, Brennan $P$, Tjonneland $A$, et al. A risk model for lung cancer incidence. Cancer Prev Res (Phila) 2012;5 834-46.

29. Brenner DR. Cancer incidence due to excess body weight and leisure-time physical inactivity in Canada: implications for prevention Prev Med 2014;66:131-9.

30. Labarthe DR, Stamler J. Improving cardiovascular health in a rural population: can other communities do the same?. JAMA 2015;313:139-40.

31. Nissinen A, Tuomilehto J, Salonen JT, et al. The influence of socioeconomic factors on blood pressure control during a community-based hypertension control programme. Acta Cardiol 1986;41:99-109.

32. Kaplan GA, Salonen JT. Socioeconomic conditions in childhood and ischaemic heart disease during middle age. BMJ 1990;301:1121-3.

33. Greiser E. Closing the social gap? Midterm results of the German Cardiovascular Prevention Study in Bremen City. Circulation 1992;85:868.

34. Fortmann SP, Williams PT, Hulley SB, et al. Does dietary health education reach only the privileged? The Stanford Three Community Study. Circulation 1982;66:77-82.

35. Winkleby MA, Fortmann SP, Rockhill B. Trend in cardiovascular disease risk factors by educational level: the Stanford Five-City Project. Prev Med 1992;21:592-601.

36. Long $\mathrm{GH}$, Simmons RK, Norberg M, et al. Temporal shifts in cardiovascular risk factor distribution. Am J Prev Med 2014;46:112-21.

37. WHO. Commission on Social Determinants of Health (CSDH) IER/ EQH. Geneva, 2007.

38. Lindholm L, Rosen M, Weinehall L, et al. Cost effectiveness and equity of a community based cardiovascular disease prevention programme in Norsjo, Sweden. J Epidemiol Community Health 1996:50:190-5.

39. Record NB, Onion DK, Prior RE, et al. Community-wide cardiovascular disease prevention programs and health outcomes in a rural county, 1970-2010. JAMA 2015;313:147-55.

40. Mittelmark MB, Hunt MK, Heath GW, et al. Realistic outcomes: Lessons from community-based research and demonstration programs for the prevention of cardiovascular diseases. Public Health Policy 1993;14:438-62.

41. Weinehall L. Partnership for health: on the role of primary health care in a community intervention programme. [Doctoral thesis]. Umeå University, 1997.

42. Lingfors $\mathrm{H}$, Persson LG, Lindstrom $\mathrm{K}$, et al. Effects of a global health and risk assessment tool for prevention of ischemic heart disease in an individual health dialogue compared with a community health strategy only results from the Live for Life health promotion programme. Prev Med 2009;48:20-4.

43. Lingfors $\mathrm{H}$, Persson LG, Lindstrom $\mathrm{K}$, et al. Time for a "vision zero" concerning premature death from ischaemic heart disease?. Scand J Prim Health Care 2002;20:28-32.

44. Administrative Report. Umeå: Västerbotten County Council, 2002. 